\title{
Estrutura espacial e mobilidade urbana: estudo sistêmico aplicado à Região Metropolitana de Goiânia ${ }^{1}$
}

\author{
Space structure and urban mobility: systemic study applied to the Metropolitan Region of \\ Goiânia
}

\author{
Yordana Dias das Neves Naciff \\ Arquiteta e Urbanista. Especialista em Docência do Ensino Superior. \\ Mestranda em Arquitetura e Urbanismo na \\ Universidade Federal de Goiás, Brasil \\ yordanad.neves@gmail.com

Erika Cristine Kneib
Arquiteta e Urbanista. Mestre e Doutora em Transportes.
Pós-doutorado em mobilidade urbana.
Docente na Universidade Federal de Goiás, Brasil
erikacristine.st@gmail.com

\section{Resumo}

A dificuldade de se compreender a organização das cidades instiga a busca por descobrir uma lógica na dinâmica urbana de maneira mais abrangente e não fragmentada. Trazer o pensamento sistêmico para o urbanismo, ou seja, assumir as cidades enquanto sistemas complexos, oferece uma possibilidade de abordagem integral do espaço urbano. Neste trabalho, considera-se que a estrutura espacial da cidade é um macrossistema repleto de campos a serem investigados, buscando a compreensão das relações entre esses campos e suas interações com a cidade. A mobilidade urbana, enquanto uma das áreas de análise, é considerada um campo essencial para o entendimento da estrutura socioeconômica e espacial intraurbana, conectando pessoas ao território urbano. Esse estudo adota como base a análise sistêmica aplicada à mobilidade dentro do contexto da estrutura espacial urbana. Objetiva-se, para tal, identificar e analisar as relações entre a estrutura espacial e a mobilidade urbana na Região Metropolitana de Goiânia (RMG). A pesquisa é de natureza básica, exploratória, descritiva e baseada principalmente em análises quali-quantitativas. Adota-se o uso da análise espacial georreferenciada a partir de um modelo inferencial que busca expor a relação entre eixos escolhidos. O modelo adotado é o de autocorrelação espacial, construído a partir de uma análise exploratória para identificação de localizações atípicas (outliers) e padrões de associação espacial (clusters) por meio de mapas das variáveis em estudo. Como resultado da pesquisa, explora-se as relações existentes entre a estrutura espacial e a mobilidade urbana na RMG testando a hipótese de a teoria sistêmica ser uma ferramenta capaz de auxiliar na compreensão de relações urbanas.

Palavras-chave: Estrutura espacial; Mobilidade urbana; Região Metropolitana de Goiânia; Análise sistêmica.

\begin{abstract}
The difficulty of understanding the organization of cities instigates the search to discover a logic in urban dynamics in a more comprehensive and non-fragmented way. Bringing systemic thinking into urbanism, assuming cities as complex systems, offers a possibility for an integral approach to urban space. This work considers that the spatial structure of the city is a macrosystem full of fields to be investigated, seeking to understand the relationships between these fields and their interactions with
\end{abstract}

\footnotetext{
${ }^{1}$ Pesquisa financiada pela CAPES - Coordenação de Aperfeiçoamento de Pessoal de Nível Superior.
} 
the city. Urban mobility is one of the areas of analysis and is a required field for understanding the intra-urban socioeconomic and spatial structure for connecting people to urban territory. This study is based on systemic analysis applied to mobility in the context of urban spatial structure. The objective is to identify and analyze the relationships between spatial structure and urban mobility in the Metropolitan Region of Goiânia. The research is basic, exploratory, descriptive and based mainly on qualitative and quantitative analyzes. The use of georeferenced spatial analysis is adopted from an inferential model that seeks to expose the relationship between the chosen axes. The adopted model is the spatial autocorrelation, built from an exploratory analysis to identify atypical locations (outliers) and spatial association patterns (clusters). As a result of the research, the relationship between spatial structure and urban mobility in the Metropolitan Region of Goiânia is explored by testing the hypothesis that systemic theory is an able tool to help to understand public relations.

Keywords: Spatial structure; Urban mobility; Metropolitan Region of Goiânia; Systemic analysis.

\section{INTRODUÇÃO}

As cidades são territórios complexos. Constituídas por inúmeros atores e atividades, à medida em que as cidades vão se expandindo e se alterando, os problemas e desafios inerentes à organização do território vão se agravando nos mais diversos campos e atividades urbanas. Estudar as cidades, consiste, portanto, em compreender que esse objeto das ciências em geral demanda alta complexidade de interpretação. É um objeto de estudo interdisciplinar, a maior, mais contraditória e mais complexa estrutura feita pelo homem (FERREIRA, 2011).

Zechlinski (2013, p.1) ressalta a importância de compreensão desse território heterogêneo das cidades a partir do estudo da estrutura espacial urbana que "revela a ordenação dos espaços segundo a importância que eles adquirem na malha urbana". A autora complementa ainda que a estrutura espacial é "a base a partir da qual a cidade se desenvolve e as pessoas interagem entre si e com o ambiente urbano". É configurada pela junção de elementos em uma mesma rede de relações que, quando conectados, influenciam na estruturação espacial da cidade em uma alteração complexa e constante.

São diversos os elementos e sistemas urbanos que se relacionam com a estrutura espacial da cidade, como a mobilidade, espraiamento urbano, infraestrutura e uso do solo, meio ambiente, segregação urbana, segurança pública, dentre outros. Kasemsook (2003) comprova a existência de uma forte inter-relação entre a estrutura espacial, o padrão de movimentação e a distribuição dos serviços, ou seja, o padrão de uso do solo. Nessa vertente, é possível identificar a importância que o sistema da mobilidade urbana estabelece com a estrutura espacial urbana.

Segundo Brito e Kneib (2016, p.97) a mobilidade urbana está relacionada à “capacidade de deslocamento das pessoas e cargas no espaço urbano". É uma área de análise indispensável para a estrutura espacial e ordenamento das cidades por conectar as pessoas ao território urbano. Portugal e Mello $(2017$, p.2) complementam ainda que à medida que as cidades evoluem e se tornam mais 
complexas, "torna-se mais visível e requerido aplicar-se um olhar multimodal e intersetorial", enfatizando o conceito sistêmico de mobilidade da atualidade.

A dificuldade de apreender e compreender a organização das cidades, assim como prever seu funcionamento, instiga a busca por descobrir uma lógica na dinâmica urbana. Nessa perspectiva, a ferramenta de investigação sistêmica aspira ser um método admissível para a discussão das cidades em uma abordagem integral, favorecendo uma visão total desse sistema. Trata-se de uma maneira sintética, sistemática e estrutural de olhar as cidades a partir do estudo da forma, dos seus elementos e das relações estabelecidas entre esses elementos (ZECHLINSKI, 2013).

A partir da contextualização da problemática, esse estudo se fundamenta nos seguintes questionamentos: Quais as relações entre estrutura espacial e mobilidade urbana na Região Metropolitana de Goiânia? Como identificar tais relações?

A pesquisa busca, portanto, ser uma contribuição teórica, que adota como base a análise sistêmica aplicada à mobilidade dentro do contexto da estrutura espacial urbana. Objetiva-se, para tal, identificar e analisar as relações entre a estrutura espacial e a mobilidade urbana na Região Metropolitana de Goiânia (RMG) e, ainda, testar a hipótese de a teoria sistêmica ser uma ferramenta capaz de auxiliar na identificação e compreensão dessas relações urbanas.

Visando atingir ao objetivo geral desse trabalho, o presente artigo utiliza recursos como pesquisas bibliográficas, estudo de caso, dados em bases oficiais e dados georreferenciados. A escolha da Região Metropolitana de Goiânia enquanto estudo de caso para a pesquisa levou em consideração que esse território ilustra, claramente, a formação de uma estrutura espacial fragmentada repleta de problemas a serem ainda solucionados, notadamente no campo da mobilidade urbana.

Para tanto, esse artigo se estrutura em três partes. Inicialmente há a construção de um embasamento teórico acerca dos temas da pesquisa, a partir de contextos e conceitos sobre a estrutura espacial e mobilidade urbana. De maneira conseguinte, apresenta-se o método de análise utilizado nesse estudo e, por fim, tem-se a aplicação do procedimento metodológico: a avaliação da relação entre estrutura espacial e mobilidade urbana na Região Metropolitana de Goiânia.

\section{BASES TEÓRICAS}

Visando construir uma linha de percepção coerente com os objetivos e estruturação dessa pesquisa, esse capítulo visa a compressão dos principais conceitos que embasam esse estudo: estrutura espacial e mobilidade urbana. Objetiva-se levantar e construir a fundamentação teórica necessária para o desenvolvimento das aplicações e análises dos capítulos subsequentes. Para tanto, nesse capítulo, será utilizada pesquisa bibliográfica e documental enquanto metodologia para a formulação do conteúdo em uma abordagem qualitativa. 


\subsection{Estrutura Espacial Urbana}

As conformações da estrutura territorial das cidades, de acordo com Kneib (2014, p.8), se fundamentam, basicamente, na existência de centralidades: os centros e os subcentros urbanos. Para a autora, a estrutura espacial urbana é entendida enquanto o agrupamento de "atividades, funções urbanas e a maneira como se organizam e articulam espacialmente". De maneira análoga, Catalão (2010) discute que, para conformar um espaço territorial metropolitano, há a necessidade de uma relação dinâmica de serviços e atividades diversas entre as redes urbanas.

Zechlinski (2013, p.13) complementa que a análise da estrutura espacial ou morfologia urbana consiste basicamente no "estudo da forma urbana, seus elementos, características e as relações estabelecidas entre esses elementos e os processos de transformação e modificação do espaço urbano". Trata-se de uma estrutura complexa devido à existência de uma junção de elementos em uma mesma rede de relações.

Castro et al. (2015, p.176) apresentam o processo de estruturação das cidades se baseando, sobretudo, na estruturação viária que, devido à alta influência "no uso e ocupação do solo urbano, [...] possibilita deslocamentos humanos e trocas de informação e mercadorias". Essas interfaces rodoviárias-urbanas são sustentadas pelas migrações e deslocamentos constantes das ocupações populacionais - assuntos relacionados intrinsecamente ao sistema da mobilidade urbana.

De maneira análoga, Harris (2015) discorre que a estrutura espacial urbana é entendida pela relação entre a alocação das atividades e os padrões de viagem resultantes. Isso se refere de maneira similar ao conceito de Castro et al. (2015) por definir a estrutura espacial pelas relações entre pessoas, mercadorias e informações, podendo assim ser avaliada pelos sistemas de transporte das cidades.

Como visto, a estrutura espacial possui vários conceitos e, nessa perspectiva, também pode ser caracterizada de diversas formas. Para Ojima (2007), a estrutura espacial é caracterizada por quatro fatores: densidade, fragmentação, orientação e centralidade. Tais aspectos também são amplamente discutidos por Harris (2015). O autor associa tais fatores a três grandes grupos que geram impactos diferentes entre a proximidade de atividades e a mobilidade dos atores: escala, arranjo de densidades e arranjo das atividades.

É importante observar que a cidade apresenta uma dicotomia entre a sua estrutura física (uso do solo, redes, habitações) e a sua estrutura social (renda, empregos, população). Esses aspectos, segundo Harris (2015), auxiliam na identificação e compreensão da estrutura espacial de uma cidade por ressaltar as áreas mais desenvolvidas e as mais subutilizadas.

Nesta pesquisa, a estrutura espacial urbana é entendida enquanto a materialidade física da cidade (ou forma urbana) composta por diversos elementos em constante interação e mutação - um verdadeiro macrossistema urbano. Como o presente trabalho almeja a exploração de dados 
quantitativos, para caracterizar a estrutura espacial se investigará três aspectos que traduzem, sinteticamente, a estrutura urbana física e social da área em estudo: distribuição de renda, concentração populacional e acesso aos serviços públicos (representada pela coleta de lixo e abastecimento de água da rede geral).

\subsection{Mobilidade urbana}

A mobilidade urbana é uma área de análise indispensável para a compreensão da estrutura espacial, do ordenamento dos territórios e da conformação de redes urbanas. Tem-se, frequentemente, a ligação do termo com os deslocamentos urbanos e o uso do solo, no entanto, o conceito de mobilidade urbana ainda não se consolidou por completo, permitindo assim que as definições relacionadas ao termo sejam diversas (BRITO; KNEIB, 2016).

A mobilidade urbana, de maneira geral, é representada por todos movimentos urbanos, sejam eles motorizados ou não. Segundo Portugal e Mello (2017), são os deslocamentos realizados para se desenvolver atividades, podendo ser expressa, portanto, por padrões de viagens com foco nas atividades urbanas. Brito e Kneib (2016, p. 97) definem de maneira similar a mobilidade urbana, relacionando-a à "capacidade de deslocamento das pessoas e cargas no espaço urbano".

Conforme tais definições, é possível notar a associação entre os conceitos de mobilidade, acessibilidade (facilidade de alcançar as atividades) e transportes (infraestrutura e serviços destinados aos deslocamentos de pessoas e mercadorias). Ressalta-se ainda que essa relação estabelecida entre esses elementos impacta diretamente no planejamento e no desenvolvimento urbano de toda cidade ou região metropolitana (PORTUGAL; MELLO, 2017).

Segundo Brito e Kneib (2016, p. 96), existem muitas variáveis que afetam e são afetadas pela mobilidade urbana, sejam elas de forma direta "pelos sistemas de transporte e uso do solo", ou de forma indireta por "diversas variáveis como segurança, políticas sociais, ambientais, econômicas, educação, entre outras". Essa complexidade em torno do tema da mobilidade requer que, na atualidade, aplique-se um olhar multimodal e intersetorial nas cidades, ou seja, um olhar mais abrangente, do tipo sistêmico (PORTUGAL; MELLO, 2017).

A questão da mobilidade, por envolver diversas políticas, se torna um tema muito abrangente e desafiador. Nessa pesquisa, a mobilidade urbana será definida pelos deslocamentos das pessoas e cargas no espaço urbano, abrangendo os fluxos motorizados e não-motorizados. Para a caracterização desse sistema urbano, foram selecionadas duas variáveis de avaliação a partir da abordagem de diversos autores (KNEIB, 2014; PIRES, 2018; GONZAGA, 2017): sistema viário e transporte público coletivo. 


\section{ASPECTOS METODOLÓGICOS E FERRAMENTAIS}

A análise sistêmica se configura, nessa pesquisa, enquanto hipótese e método. Dessa forma, esse capítulo visa descrever a metodologia sistêmica, construindo um embasamento consistente para a compreensão das ferramentas de abordagem sistêmica que são aplicadas no capítulo seguinte.

A Teoria Geral dos Sistemas (TGS) emergiu enquanto um novo movimento científico, na metade do século XX, apresentando uma variedade de abordagens e aplicações para lidar com a complexidade e transformações nas mais variadas áreas do conhecimento (KASPER, 2000). Essa teoria reconhece a existência de um "todo organizado" formado por elementos interconectados que possuem um objetivo comum (MACEDO et al., 2008). Trata-se da compreensão dos fenômenos de forma mais abrangente dentro de um contexto maior.

Compreendendo enquanto "sistema" um complexo amplo formado por um conjunto de elementos em interação entre si e em intercâmbio constante com o meio, Oliveira e Portela (2006, p.168) definem a TGS enquanto uma teoria intuitiva e simples. Para as autoras, cada sistema "é composto por subsistemas ou componentes e está integrado num macrossistema", sendo o "todo" superior à soma das partes que o compõe.

Tanto a estrutura espacial quanto a mobilidade urbana são compostas por uma variedade de elementos que apresentam funções e comportamentos múltiplos, estão em incessante evolução e possuem uma grande variedade de inter-relações. Dessa forma, as duas temáticas se inserem adequadamente nas características de um "sistema", podendo assim, serem classificadas e analisadas como tal.

Sob essa perspectiva, trazer o pensamento sistêmico para o urbanismo, ou seja, assumir as cidades enquanto sistemas complexos, oferece uma possibilidade de abordagem integral do espaço urbano. Neste trabalho, considera-se a estrutura espacial da cidade como um macrossistema repleto de campos a serem investigados, principalmente quando se busca a compreensão das relações entre esses campos e suas interações com a cidade. A mobilidade urbana, enquanto uma das áreas de análise, é considerada um sistema urbano essencial para o entendimento da estrutura espacial intraurbana, visto que conecta pessoas ao território urbano.

Para tal, a metodologia adotada consiste em uma análise espacial georreferenciada a partir de um modelo inferencial que busca expor a relação entre eixos escolhidos. O modelo adotado é o de autocorrelação espacial, construído a partir de uma análise exploratória para identificação de localizações atípicas (outliers) e padrões de associação espacial (clusters) por meio de mapas das variáveis em estudo (RIGOTTI, 2005; NETO; KNEIB, 2016; CHAGAS, 2016; DRUCK et al., 2005).

Como suporte para a elaboração dos mapas, foram utilizados arquivos vetoriais no formato shapefile e tabelas .xls disponibilizados em bases oficiais como o Instituto Brasileiro de Geografia e 
Estatística (IBGE), Sistema Estadual de Geoinformação de Goiás (SIEG) e Redemob Consórcio. Os dados foram manipulados no software ArcGis v.10.6 para o desenvolvimento e geração dos mapas temáticos.

A escala cartográfica definida para essa análise é a de setores censitários. Além de representar a menor unidade territorial, a disponibilidade de dados dos setores censitários permite elaborar, de maneira mais precisa, análises comparativas nas cinco variáveis selecionadas. Nesse sentido, essa escala representa um grande potencial para o desenvolvimento da análise sistêmica proposta.

Dessa forma, o procedimento metodológico sistêmico desenvolvido para essa pesquisa se apresenta em três etapas - consistindo em várias sobreposições sistêmicas de informações urbanas. Primeiramente são elaborados os mapas sínteses dos dois eixos de análise a partir da sobreposição das variáveis escolhidas para a estrutura espacial (distribuição de renda, concentração populacional e acesso a serviços públicos) e para a mobilidade urbana (sistema viário e transporte público coletivo). De maneira conseguinte, os dois mapas sínteses são sobrepostos a fim de resultar em um mapa geral que permitirá, por fim, uma leitura integral do espaço urbano (Fig. 1).
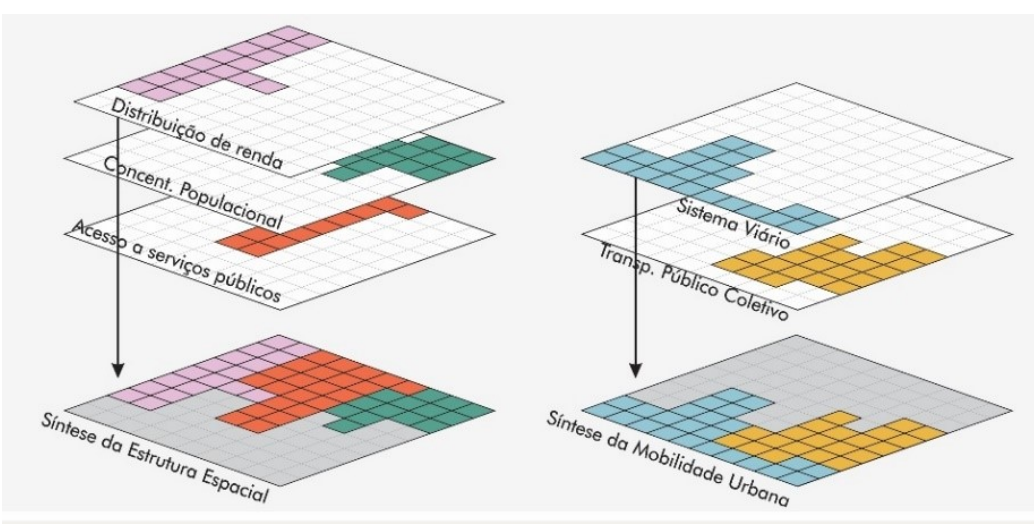

1) Elaboração de Mapas Sínteses de cada sistema a partir da sobreposição das variáveis urbanas selecionadas
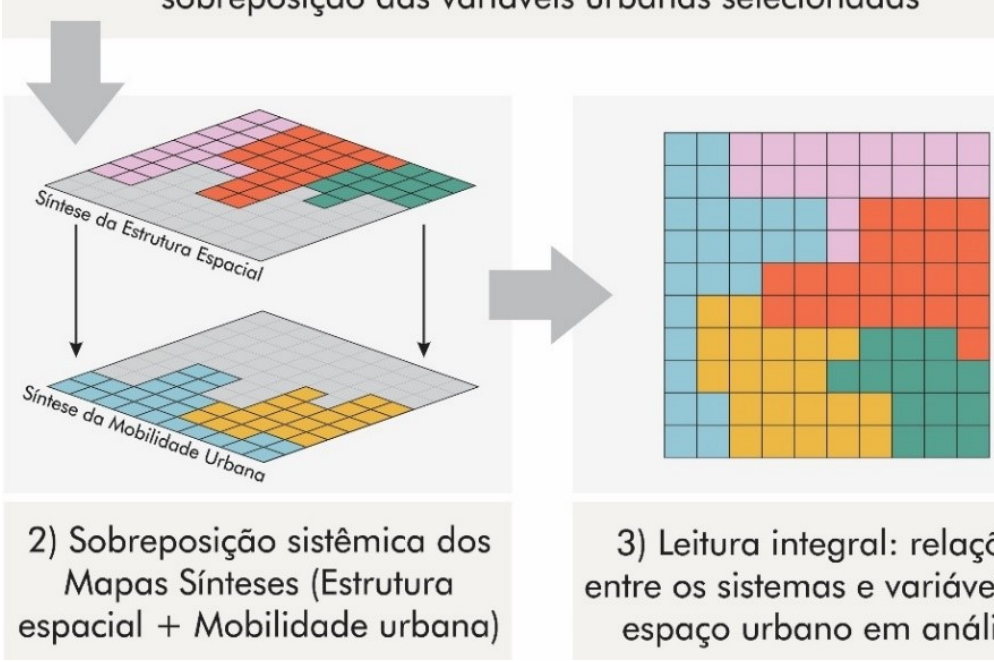

3) Leitura integral: relações entre os sistemas e variáveis no espaço urbano em análise

Figura 1 - Metodologia sistêmica adotada na pesquisa para a análise de variáveis urbanas.

Fonte: Elaborado pelos autores. 
Para a compreensão global da relação entre a estrutura espacial e a mobilidade urbana, estabeleceu-se a existência de um modelo espacial contínuo (levando à ideia de dissolução dos limites das áreas em superfícies contínuas) a partir do uso de interpoladores geoestatísticos. (DRUCK et al., 2004). Para tal, o desenvolvimento da estimativa da magnitude da autocorrelação espacial entre os eixos utilizou o índice de Moran ${ }^{2}$ através da identificação de clusters e outliers em cada variável da estrutura espacial. Na representação espacial, essa ferramenta resulta na tipologia de padrões COType, conforme Tabela 1.

Tabela 1 - Parâmetros de agrupamento na análise de clusters e outliers conforme padrão COType.

\begin{tabular}{|c|c|}
\hline \multicolumn{2}{|r|}{ ANÁLISE DE CLUSTERS E OUTLIERS } \\
\hline Not Significant & $\begin{array}{l}\text { Não significante: não se enquadram nos agrupamentos, pois apresentam níveis } \\
\text { variados assim como os valores dos vizinhos. }\end{array}$ \\
\hline High-High Cluster & Alta-Alta: agrupamento de valores altos e próximos. \\
\hline High-Low Outlier & $\begin{array}{l}\text { Alta-Baixa: outlier de valores altos que não se agrupam, pois se encontram em meio } \\
\text { a valores baixos. }\end{array}$ \\
\hline Low-High Outlier & $\begin{array}{l}\text { Baixa-Alta: outlier de valores baixos que não se agrupam, pois se encontram em } \\
\text { meio a valores altos. }\end{array}$ \\
\hline Low-Low Cluster & Baixa-Baixa: agrupamento de valores baixos e próximos. \\
\hline
\end{tabular}

Fonte: Adaptado de MEDEIROS (2018) pelos autores.

Os mapas de clusters e outliers das variáveis selecionadas serviram de base para o desenvolvimento do mapa síntese da estrutura espacial: isola-se os clusters, construindo um mapa com os valores extremos encontrados nas três variáveis, ou seja, agrupa-se os valores mais altos e mais baixos. Dessa forma, se torna possível identificar as localidades de maior inclusão/exclusão socioeconômica da área em estudo, possibilitando o entendimento da relação desse macrossistema com o sistema da mobilidade urbana pelo viés da polarização centro/periferia.

\section{AVALIAÇÃO DA RELAÇÃO ENTRE ESTRUTURA ESPACIAL E MOBILIDADE URBANA NA REGIÃO METROPOLITANA DE GOIÂNIA}

A Região Metropolitana de Goiânia, no Estado de Goiás, se apresenta como o objeto de estudo escolhido para as análises e aplicação teórica. Esta Região tem Goiânia como cidade-polo e, segundo o IBGE (2018), é a $13^{\mathrm{a}}$ maior concentração urbana do país, representada por 2.571.250 habitantes em um território de 7.315,10 km². Em 2010, possuía uma taxa de urbanização de 98\%, atingindo uma ocupação urbana de cerca de $60 \%$ de seu território de extensão. Concentrando grande

\footnotetext{
2 “O índice de Moran (I) é a estatística mais difundida e mede a autocorrelação espacial a partir do produto dos desvios em relação à média. Este índice é uma medida global da autocorrelação espacial e indica o grau de associação espacial presente no conjunto de dados" (CARDOSO, 2007).
} 
parte da população e serviços do estado de Goiás, a densidade populacional da RMG, segundo o IBGE (2018), se aproxima de 351,49 hab $/ \mathrm{km}^{2}$. Sua configuração atual, formada por 20 municípios ${ }^{3}$, foi constituída em 2018 com a Lei Complementar no 139 que retirou o município de Inhumas e adicionou Santa Bárbara de Goiás.

Em relação à caracterização dessa região, sua estrutura espacial denota haver uma heterogeneidade massiva no território, tendo em vista que as novas centralidades geradas pela dinâmica urbana de Goiânia caracterizam um desequilíbrio considerável entre as redes que compõem a RMG (KNEIB, 2016; GENTIL et al., 2016; GONZAGA, 2017). Kneib (2016) complementa que a estrutura espacial da cidade de Goiânia se configura, principalmente, por centralidades vinculadas estreitamente ao sistema viário e ao uso e ocupação do solo - associação ao sistema da mobilidade urbana.

Essas constatações instigam e apoiam o objetivo geral dessa pesquisa. Com isso, o estudo se desenvolverá em três etapas visando a avaliação da relação estabelecida entre a estrutura espacial e mobilidade urbana na RMG.

\section{Etapa 1: Sínteses dos eixos em análise \\ Eixo de Análise I - Estrutura espacial}

As variáveis analisadas para a construção do mapa síntese da estrutura espacial da Região Metropolitana de Goiânia, denotaram a existência de uma grande heterogeneidade na extensão desse território. Notadamente, em todas as variáveis, as maiores concentrações - sejam elas populacionais ou socioeconômicas - estão em Goiânia e suas imediações que, de forma imperativa, conformam o grande centro da metrópole e apontam as áreas classificadas enquanto periferias metropolitanas.

Em relação a concentração populacional (Fig. 2), é possível perceber um maior adensamento no centro que se dilui à medida em que se distancia do núcleo. Apesar do plano inicial de crescimento da capital não prever extensões periféricas, no decorrer da evolução do espaço urbano, o padrão de organização da metrópole passa a repetir o tradicional modelo centro/periferia que reflete na configuração da estrutura espacial. Os valores máximos (altos e baixos) dessa concentração populacional podem ser melhor observados no mapa de clusters e outliers (Fig. 3) que apresenta, de forma gráfica, a heterogeneidade do agrupamento dos habitantes da RMG.

\footnotetext{
${ }^{3}$ Os municípios da Região Metropolitana de Goiânia: Goiânia, Abadia de Goiás, Aparecida de Goiânia, Aragoiânia, Bela Vista de Goiás, Bonfinópolis, Brazabrantes, Caldazinha, Caturaí, Goianápolis, Goianira, Guapó, Hidrolândia, Nerópolis, Nova Veneza, Santa Bárbara de Goiás, Santo Antônio de Goiás, Senador Canedo, Terezópolis de Goiás e Trindade.
} 


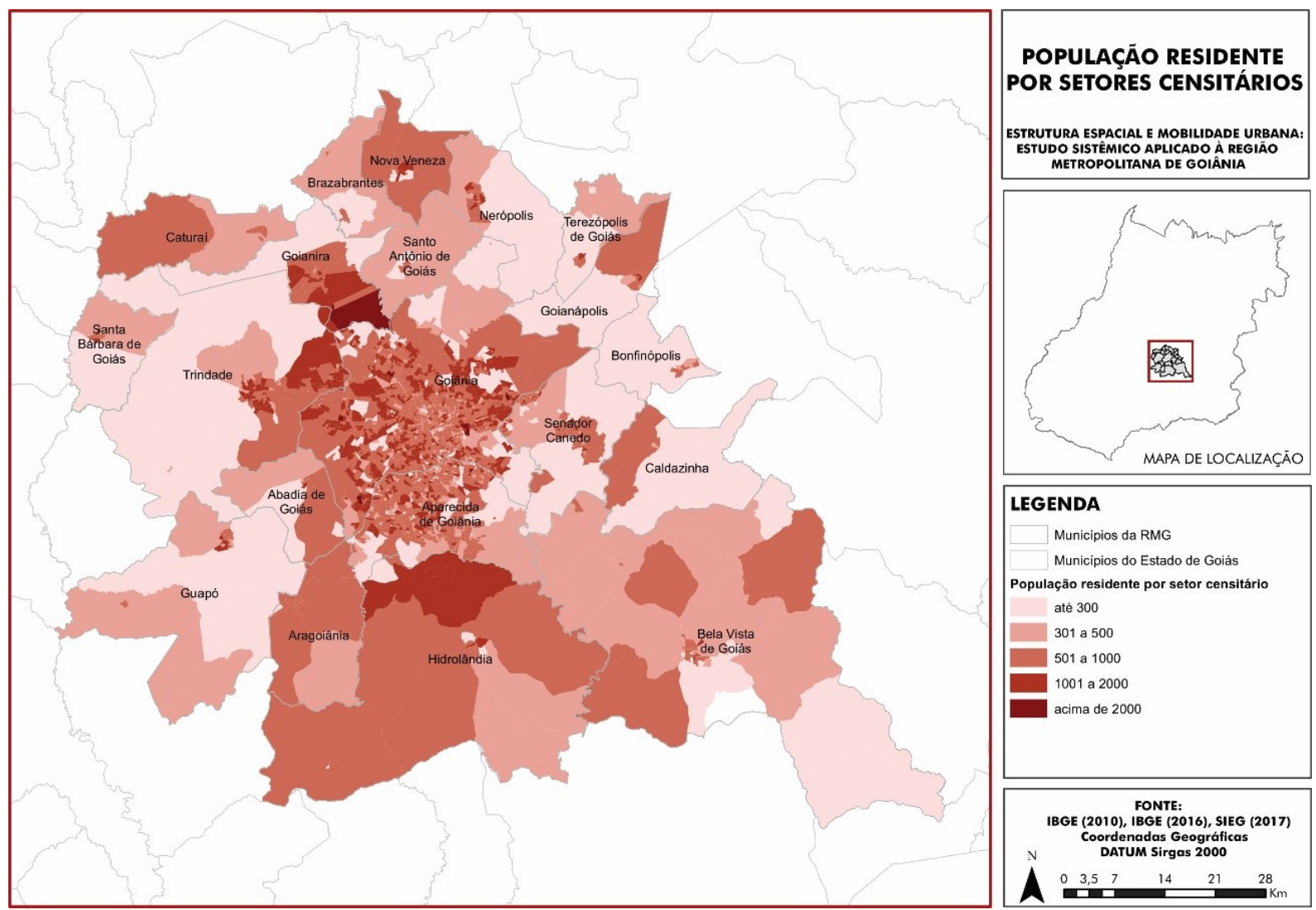

Figura 2 - População residente por setores censitários na Região Metropolitana de Goiânia. Fonte: Elaborado pelos autores.

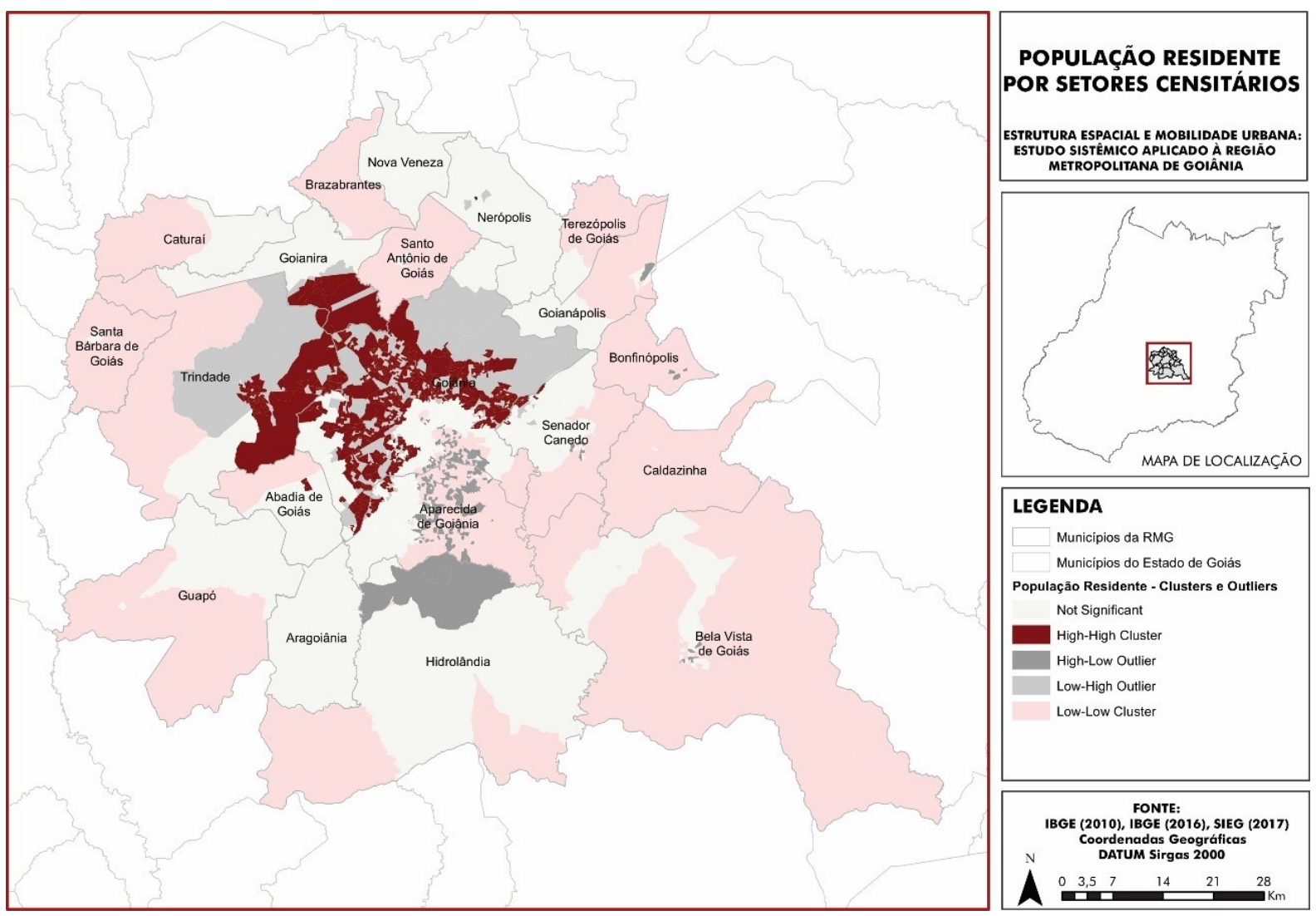

Figura 3 - Clusters e Outliers referentes à população residente da Região Metropolitana de Goiânia.

Fonte: Elaborado pelos autores. 
A variável da distribuição de renda também comprova a existência de um território marcado pela desigualdade social e econômica. Os maiores rendimentos nominais mensais domiciliar se localizam, estritamente, na cidade de Goiânia, com valores de até vinte salários mínimos (Fig. 4). Quanto aos outros municípios, nota-se uma variação do rendimento de um a dois salários mínimos, ordenando os habitantes dessas localidades na classe socioeconômica de categoria "E" (rendimento mensal de até R\$1.908,00), o que aponta que a grande maioria não consegue usufruir do padrão de vida médio da população brasileira.

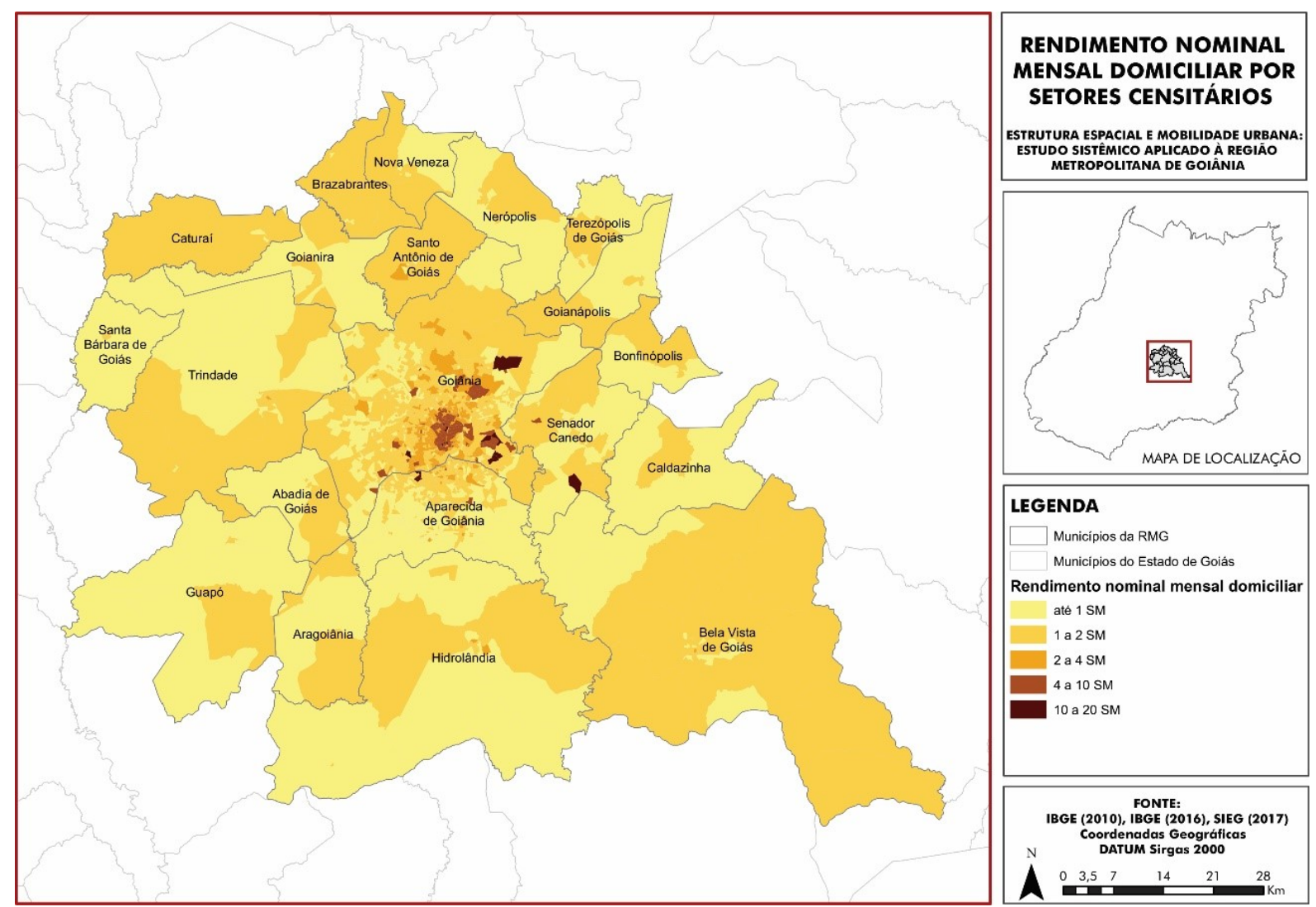

Figura 4 - Rendimento nominal mensal domiciliar por setores censitários na Região Metropolitana de Goiânia. Fonte: Elaborado pelos autores.

A partir da produção do mapa de clusters e outliers, foi possível notar que em Aparecida de Goiânia, devido à baixa divisão territorial e econômica com Goiânia, há também a presença de altas concentrações de renda (Fig.5). Dado que as economias dessas cidades estão umbilicalmente ligadas, possibilita-se afirmar que, frente aos outros 18 municípios da RMG, a desigualdade socioeconômica se apresenta de forma imperiosa controlando a quantidade de bens e serviços que os cidadãos goianiense conseguem adquirir. 


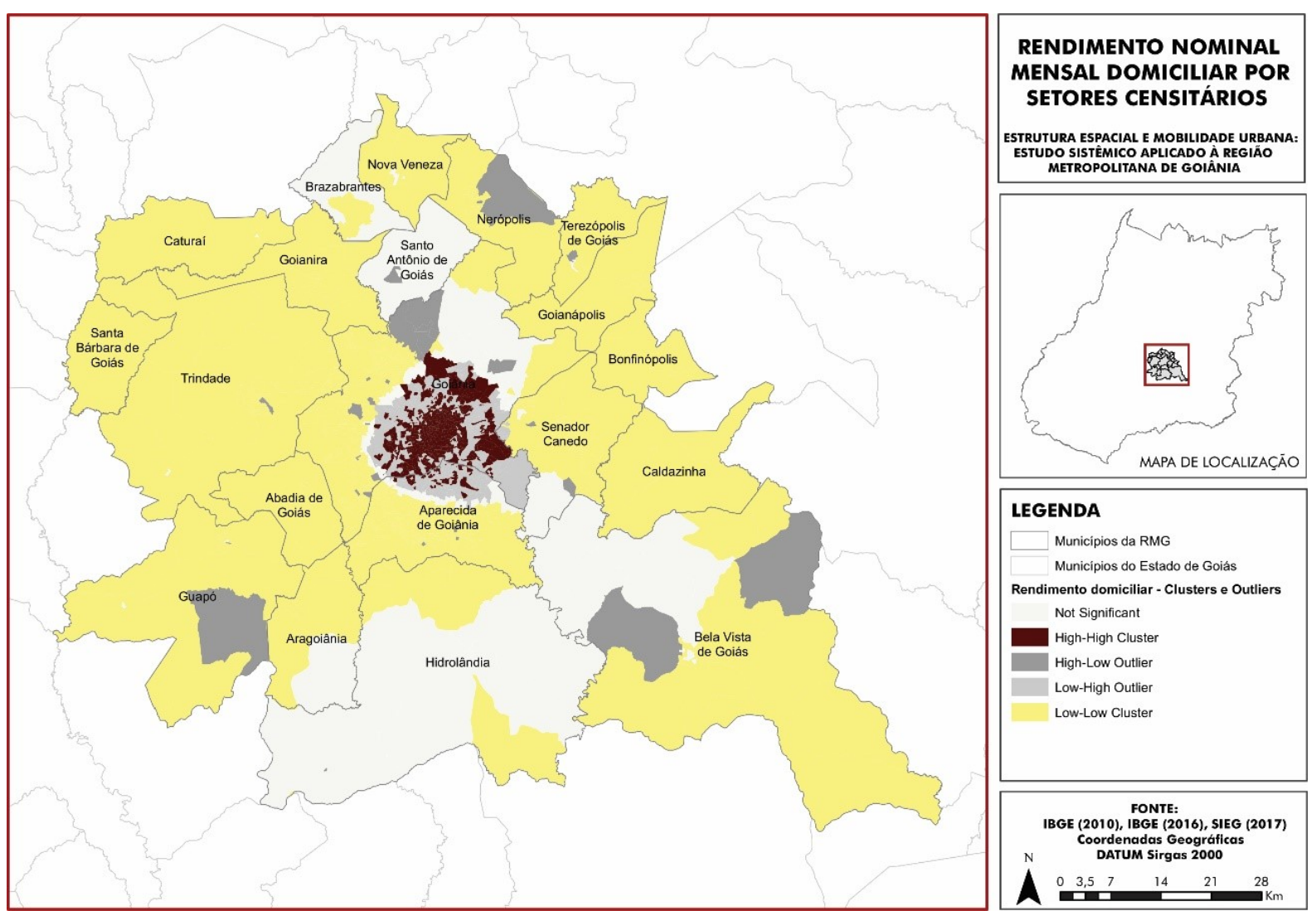

Figura 5 - Clusters e Outliers referentes ao rendimento nominal mensal domiciliar da Região Metropolitana de Goiânia. Fonte: Elaborado pelos autores.

A dicotomia centro/periferia da Região Metropolitana de Goiânia ressalta a presença de territórios marcados pela precariedade e pela escassez de assistência e de recursos. A variável de acesso à serviços públicos permite a observação de tal constatação. Foram analisados os dados obtidos pelo Censo Demográfico 2010 (IBGE, 2011) para domicílios com abastecimento de água da rede geral e coleta de lixo, denotando a mesma heterogeneidade observada nas outras variáveis (Fig. 6).

Observa-se que a extensão das áreas definidas por clusters são muito distintas. Há somente uma minoria da população - localizada no centro - que possui acesso aos serviços públicos básicos (Fig.7). O mapa ilustra ainda uma grande área marcada por um outlier do tipo Low-High, ou seja, valores baixos que não se agrupam, pois se encontram em meio a valores altos. Dessa forma, a fragmentação territorial do tecido da RMG - fruto do espraiamento urbano - se manifesta enquanto um forte fator na problemática do acesso à uma infraestrutura urbana adequada assegurada pela legislação do cidadão. 


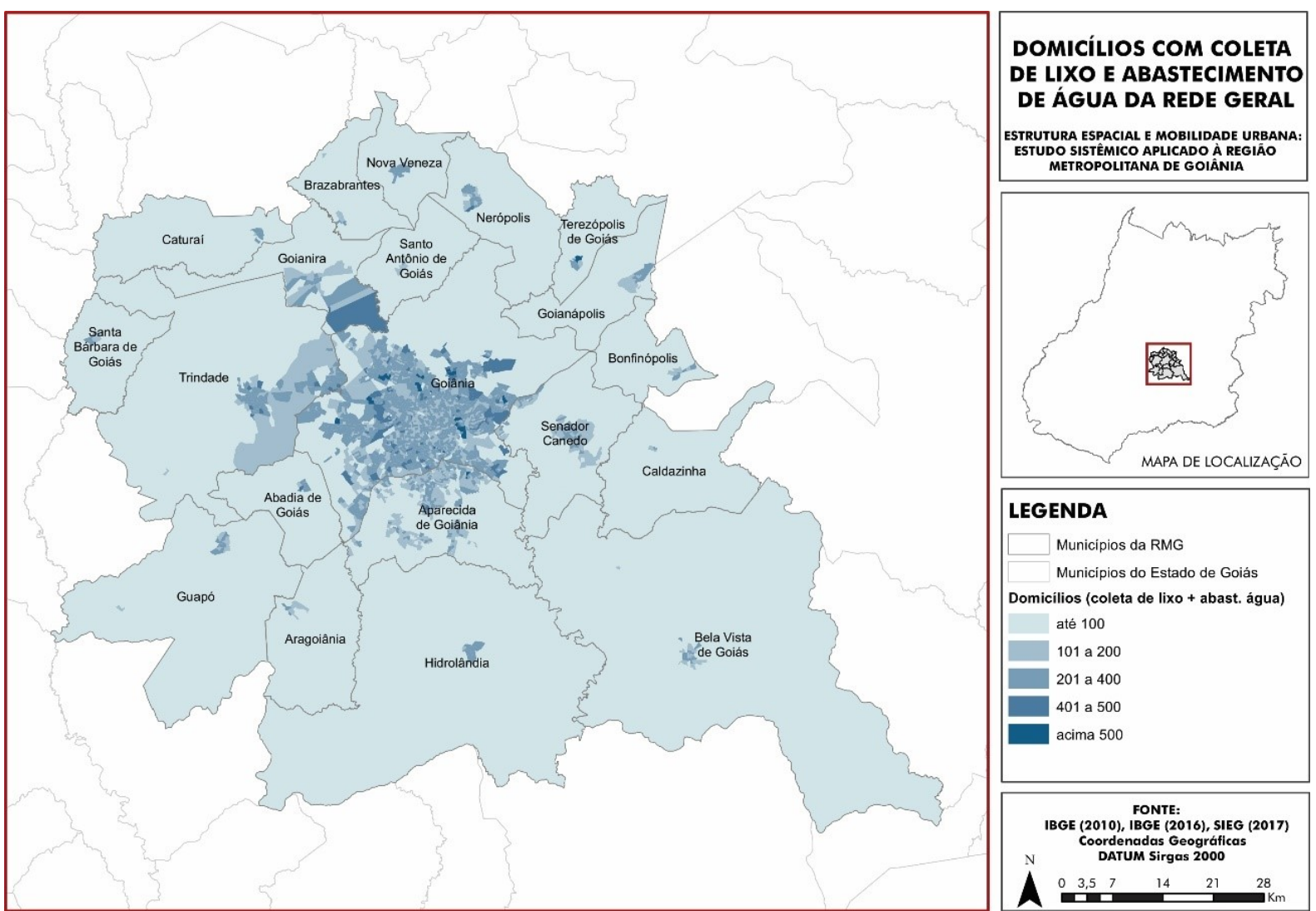

Figura 6 - Domicílios com coleta de lixo e abastecimento de água da rede geral na Região Metropolitana de Goiânia. Fonte: Elaborado pelos autores.

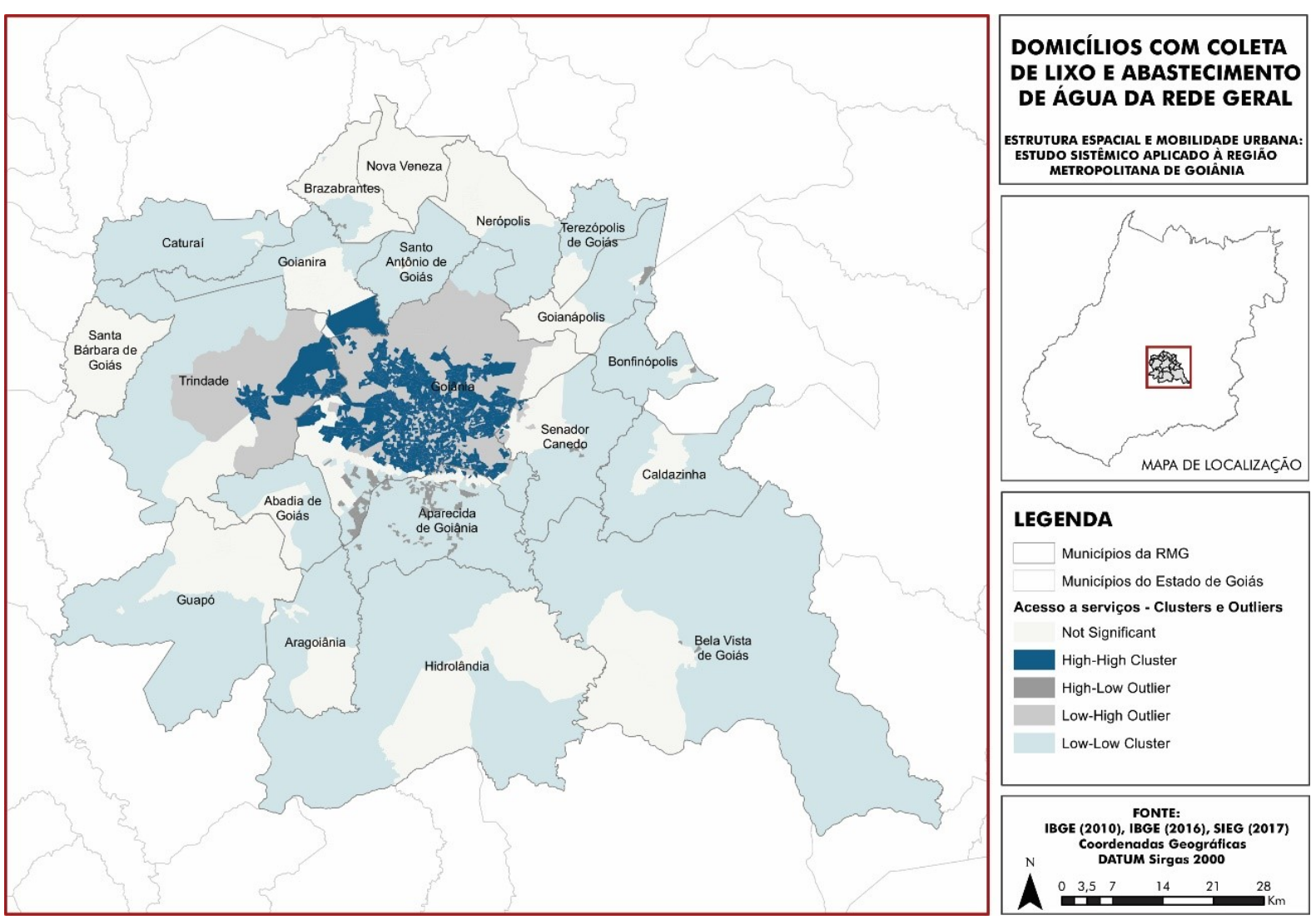

Figura 7 - Clusters e Outliers referentes ao domicílios com coleta de lixo e abastecimento de água da rede geral na Região Metropolitana de Goiânia. Fonte: Elaborado pelos autores. 
Para a construção de um mapa síntese do eixo de análise da estrutura espacial da Região Metropolitana de Goiânia, os mapas de clusters e outliers das três variáveis analisadas foram sobrepostos em uma etapa parcial, permitindo uma compreensão sistêmica das relações estabelecidas entre as variáveis e o território (Fig. 8).

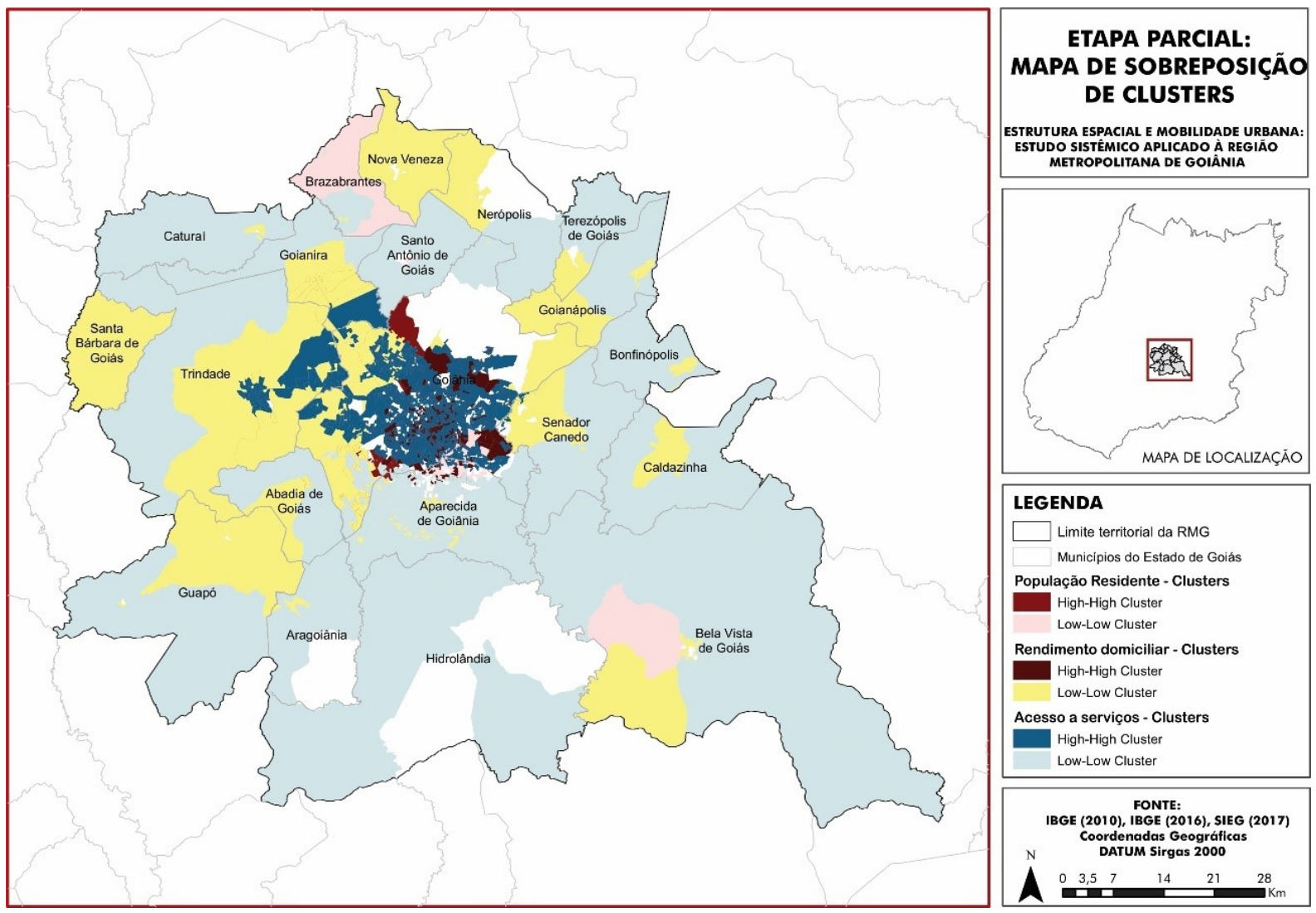

Figura 8 - Etapa parcial - mapa de sobreposição de Clusters das variáveis analisadas. Fonte: Elaborado pelos autores.

Como resultado dessa sobreposição, estabelece-se uma síntese geral para a estrutura espacial da RMG a partir da identificação dos clusters das variáveis analisadas (Fig.9). Pela sistematização realizada, foi possível evidenciar a localização dos picos extremos de concentração/alienação da estrutura espacial do território nos quesitos de distribuição de renda, concentração populacional e acesso aos serviços públicos. Dessa forma, a configuração territorial da Região Metropolitana de Goiânia é revelada pela existência de um grande centro formado principalmente pelos municípios de Goiânia, Aparecida de Goiânia, Goianira e Trindade. Retrata-se assim, a presença de uma dominância social e econômica entre esse núcleo frente aos outros municípios da RMG. 


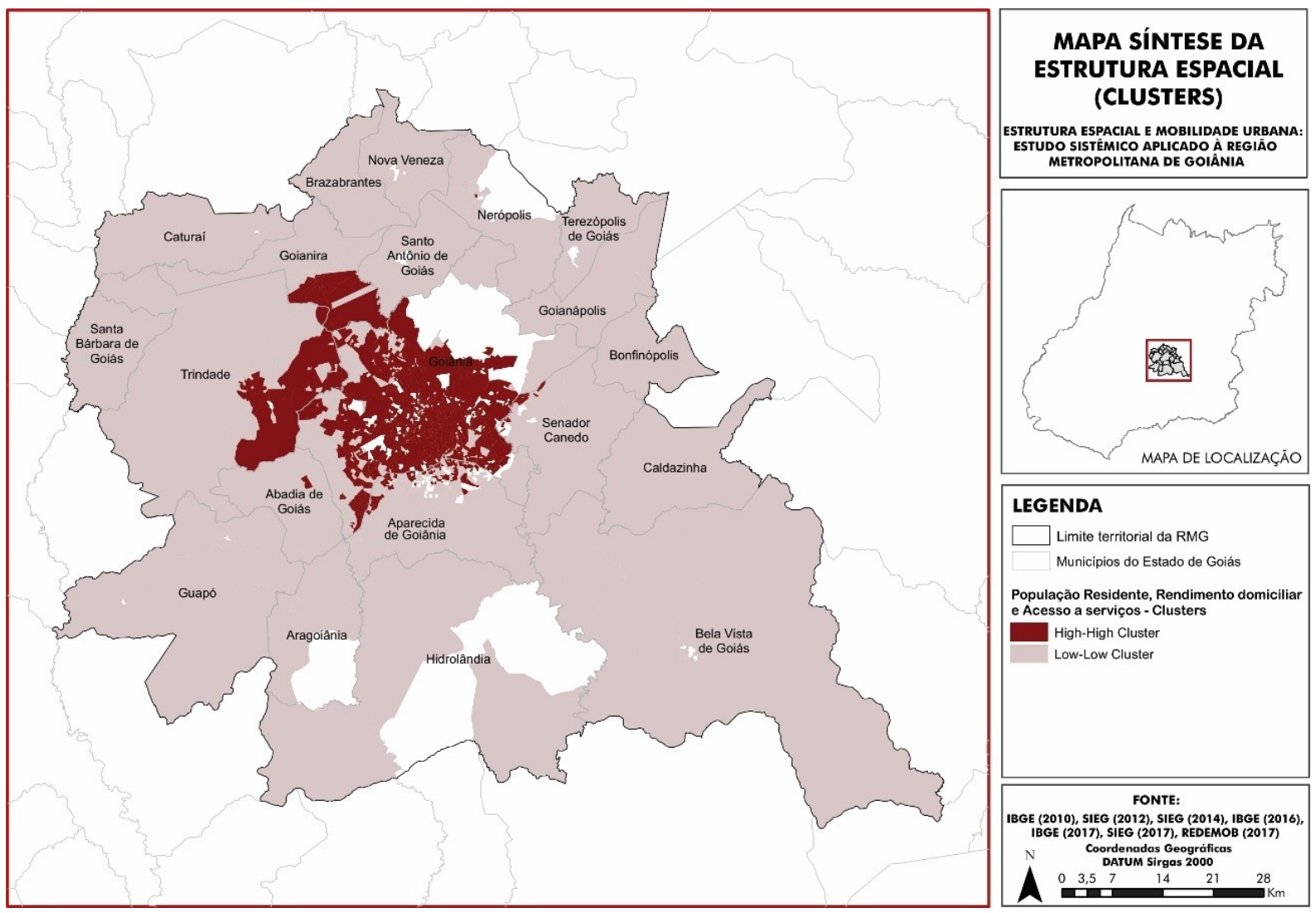

Figura 9 - Mapa síntese da Estrutura espacial da Região Metropolitana de Goiânia (Clusters).

Fonte: Elaborado pelos autores.

\section{Eixo de Análise II - Mobilidade Urbana}

O segundo Eixo de Análise desse estudo consiste na leitura da mobilidade urbana da Região Metropolitana de Goiânia a partir das variáveis do sistema viário e do transporte público coletivo. Essa análise se baseou, sobretudo, em dados vetoriais do tipo linhas e pontos, considerando vias, terminais e linhas de ônibus. Foram utilizados os mesmos critérios de sobreposição sistêmica utilizados para o Eixo de Análise I para a construção do mapa síntese. Nota-se que o sistema viário RMG (Fig.10), assim como outras cidades brasileiras, se estabelece de forma dispersa pelo território, o qual sobrecarrega o transporte público e ainda se relaciona diretamente à segregação socioespacial da população (PIRES, 2018).

O sistema unificado de transporte público coletivo da RMG é estruturado pela Rede Metropolitana de Transportes Coletivos (RMTC). A rede estrutural obedece a um modelo troncoalimentador com 21 terminais de integração e 309 linhas de ônibus (PIRES, 2018). A partir dessas informações, foram destacadas as linhas de interesse metropolitano, por onde transitam os ônibus que fazem o percurso entre municípios distintos, os terminais que concentram os fluxos de viagens e atração (Fig.11). 


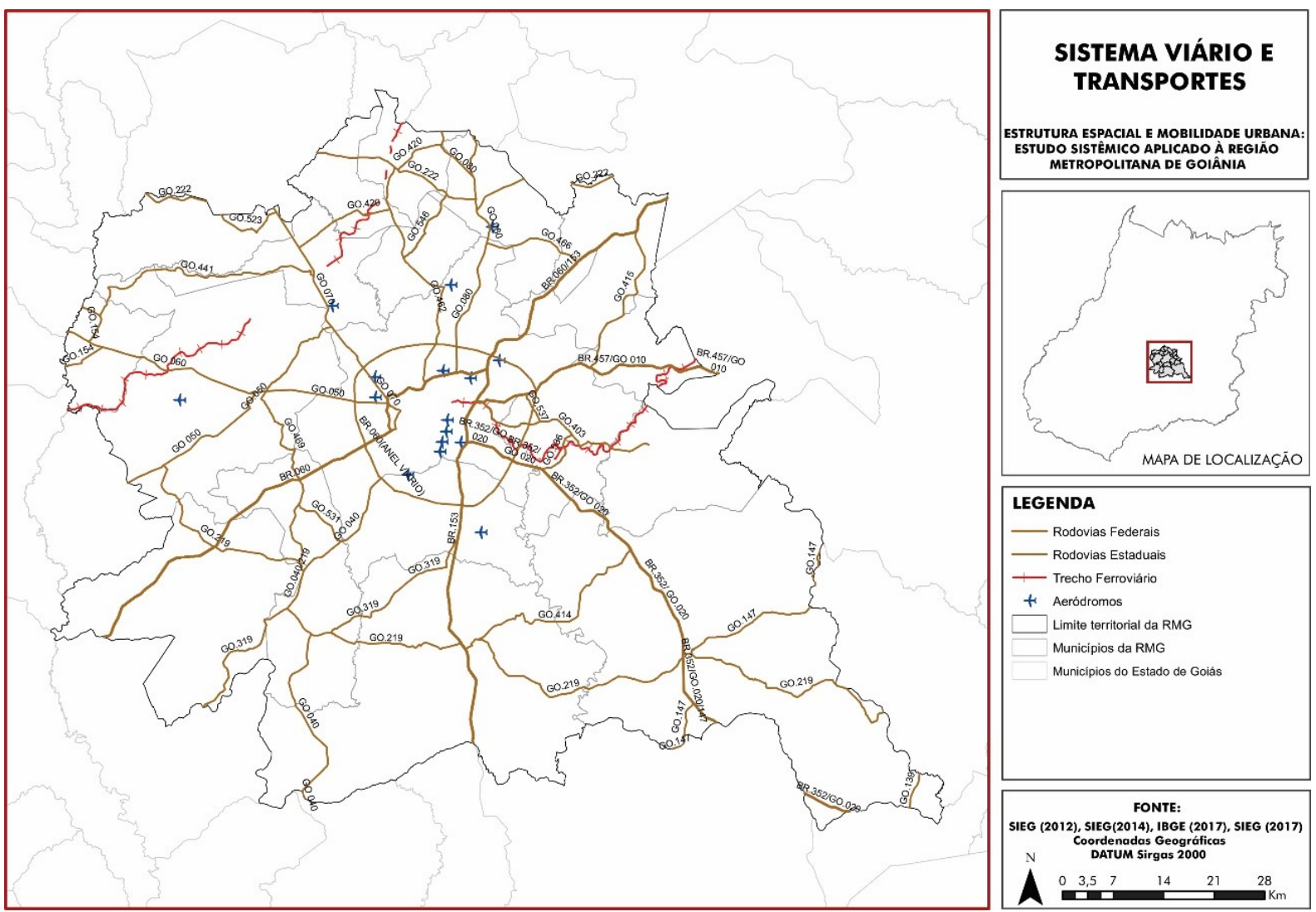

Figura 10 - Sistema viário e transportes na Região Metropolitana de Goiânia.

Fonte: Elaborado pelos autores.

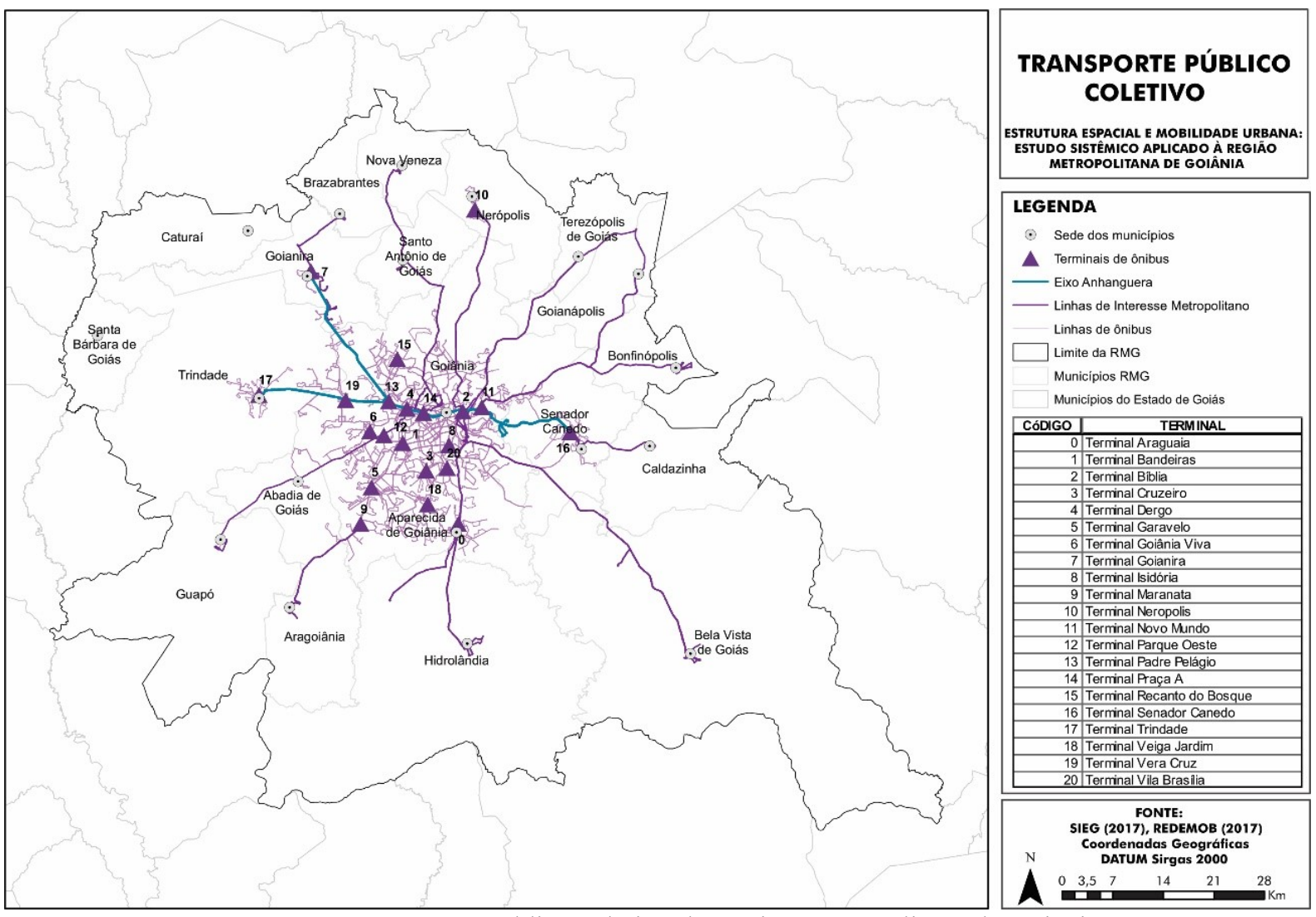

Figura 11 - Transporte público coletivo da Região Metropolitana de Goiânia.

Fonte: Elaborado pelos autores. 
A configuração espacial e as características físicas e funcionais do sistema viário e transporte público coletivo da Região Metropolitana de Goiânia, permitem um entendimento da estrutura da mobilidade urbana de forma sistêmica. A partir da sobreposição das variáveis, um mapa síntese da mobilidade da RMG foi elaborado permitindo uma visualização global da distribuição e organização desse sistema no território metropolitano (Fig. 12).

A partir dessa análise, percebe-se que as maiores concentrações de linhas estão entre as maiores concentrações populacionais, diminuindo à medida em que se afasta do centro. A disponibilidade de linhas entre $20 \mathrm{a} 30 \mathrm{~km}$ do centro da cidade-polo se restringe àquelas que utilizam a infraestrutura das rodovias intermunicipais. Denota-se, contudo, que há uma desarticulação na distribuição do sistema da mobilidade urbana - afetada pelo fenômeno do espraiamento urbano - que incita a heterogeneidade de acesso de linhas de transporte público entre o núcleo e os municípios periféricos.

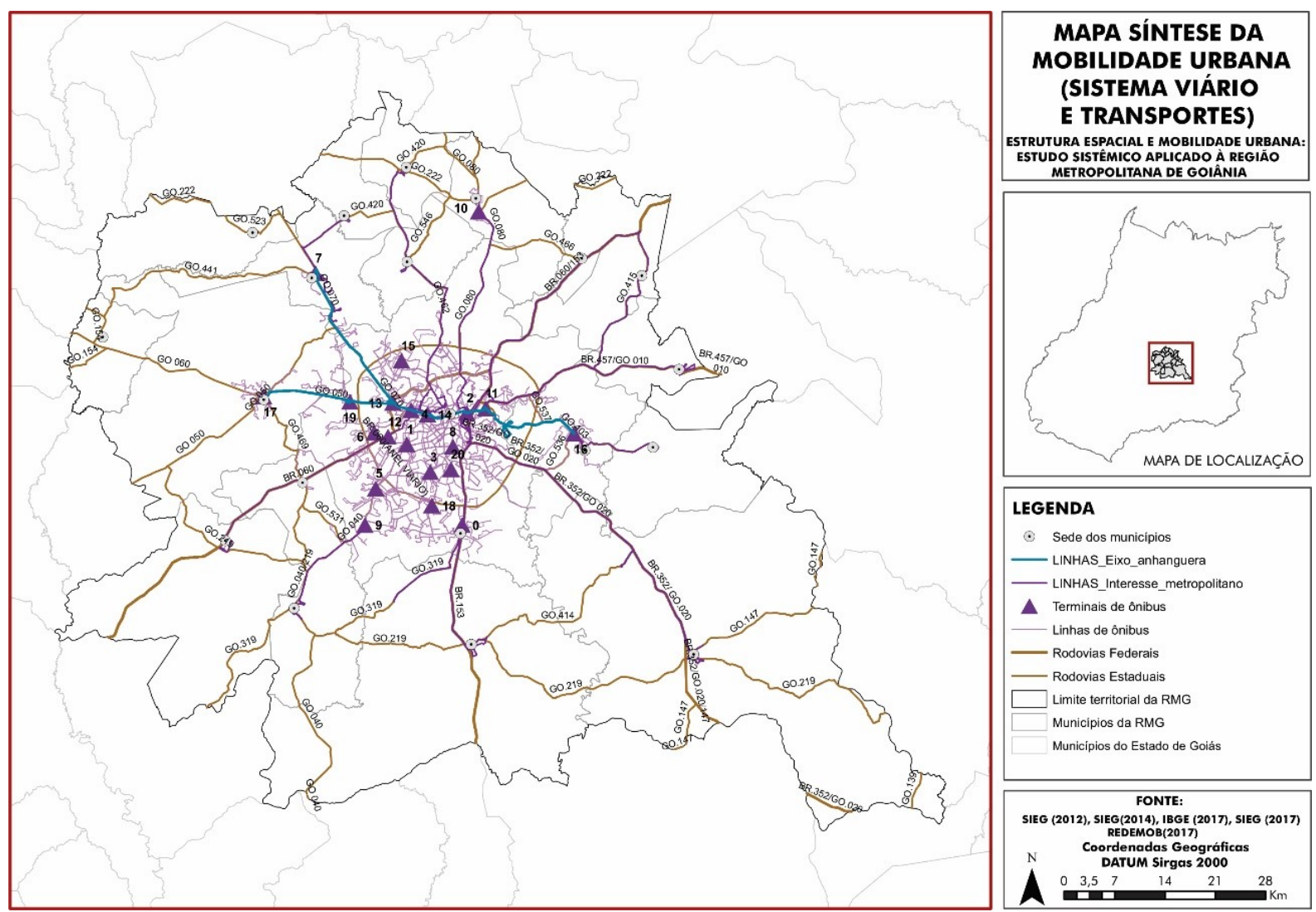

Figura 12 - Mapa síntese da Mobilidade Urbana da Região Metropolitana de Goiânia (Sistema viário e transportes). Fonte: Elaborado pelos autores.

\section{Etapa 2: Sobreposição sistêmica dos eixos em análise}

O desenvolvimento dessa etapa consiste na sobreposição sistêmicas dos mapas sínteses elaborados na seção anterior para permitir uma leitura integral da relação entre os dois eixos em análise. Visando isso, o mapa síntese da estrutura espacial (configurado a partir de clusters) foi 
sobreposto ao mapa síntese da mobilidade urbana (estruturado pelo sistema viário e transporte público coletivo) gerando uma síntese geral por um modelo espacial contínuo, adotado enquanto ferramenta metodológica nessa pesquisa (Fig. 13).

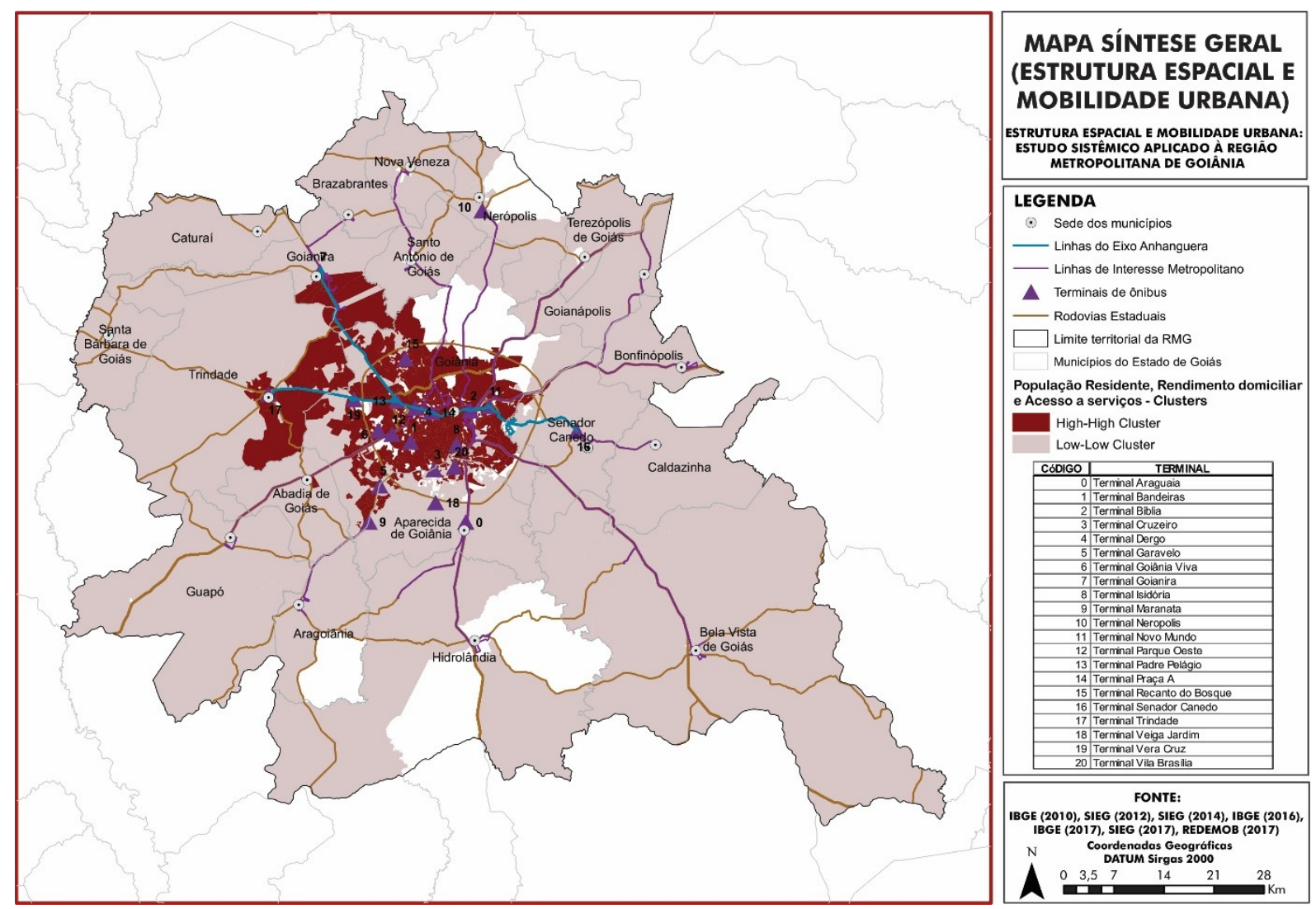

Figura 13 - Mapa síntese geral (Estrutura Espacial e Mobilidade Urbana da Região Metropolitana de Goiânia). Fonte: Elaborado pelos autores.

\section{Etapa 3: Leitura integral da relação entre os eixos em análise}

A partir do procedimento metodológico sistêmico desenvolvido para esse estudo, apresentase, como resultado, um mapa síntese geral que engloba cinco variáveis de análise concentrada em dois eixos distintos. Esses eixos são configurados enquanto sistemas que apresentam funções, comportamentos múltiplos e uma variedade de elementos em inter-relações. Tem-se a estrutura espacial enquanto o macrossistema que engloba o sistema da mobilidade urbana, uma vez que esse se configura enquanto um dos estruturadores da ocupação espacial urbana.

O mapa síntese geral desenvolvido oferece parâmetros plausíveis para o entendimento da interação entre esses campos e suas relações com a cidade (Fig. 13). Revela-se, através da demarcação dos clusters, que a estrutura urbana da Região Metropolitana de Goiânia segue marcada fortemente pelos núcleos pioneiros e pela polarização centro/periferia. Da mesma forma, a disponibilidade de linhas de transporte coletivo reforça essa distribuição desigual e salientam a falta de acessibilidade nas áreas periféricas. 
É interessante notar que os terminais urbanos se localizam, majoritariamente, na mancha determinada pelo centro da RMG. Sendo os terminais os principais elementos estruturadores da rede de transportes, essa concentração implica em uma maior integração do centro-centro e uma menor integração do centro-periferia - o que reforça a manutenção da segregação socioespacial.

A síntese elaborada revela também que o sistema da mobilidade urbana não alcança os municípios mais distantes de forma integrada, visto que inexiste uma integração por transporte público coletivo do núcleo da RMG com as cidades de Caturaí e Santa Bárbara de Goiás. Dessa forma, há a confirmação de que esses municípios são realmente caracterizados enquanto territórios periféricos dentro de uma abordagem metropolitana de relações urbanas.

Nota-se que a estrutura espacial da Região Metropolitana de Goiânia possui uma estrutura espacial com forte vínculo ao sistema viário e às centralidades populacionais e socioeconômicas. A rede estrutural do transporte coletivo se integra ao macrossistema da RMG e expõe que as relações entre os municípios não são diretas, desconectando as cidades e polarizando ainda mais as centralidades.

Em resumo, a sistematização das informações sobre a estrutura espacial e a mobilidade urbana permitiram uma leitura integral do espaço urbano metropolitano, podendo-se realizar a partir de diferentes enfoques. No caso da Região Metropolitana de Goiânia, o estudo sistêmico realizado constatou que a concentração massiva de atividades e serviços no núcleo, configura a RMG enquanto uma região heterogênea e fragmentada. Demanda-se uma descentralização dessas atuações para a mitigação dos problemas referente à mobilidade urbana, organização e gestão do território.

\section{CONSIDERAÇÕES FINAIS}

Em síntese, em meio às necessidades atuais de estudos mais abrangentes, o novo paradigma sistêmico surge orientando uma observação do "todo". Nessa perspectiva, a pesquisa se propôs a ser uma contribuição teórica que adotou como base a análise sistêmica aplicada à mobilidade dentro do contexto da estrutura espacial urbana. Dessa forma, foram analisadas as relações entre a estrutura espacial e a mobilidade urbana na Região Metropolitana de Goiânia (RMG) testando a hipótese de a teoria sistêmica ser uma ferramenta capaz de auxiliar na identificação e compreensão dessas relações urbanas.

Como resultado, analisar conjuntamente as variáveis selecionadas permitiu identificar padrões espaciais no território metropolitano que facilitaram uma leitura integral do espaço urbano. O uso de ferramentas de análise espacial baseadas em dados georreferenciados foram essenciais para a identificação das autocorrelações existentes entre os dois eixos analisados, sobretudo o desenvolvimento estatístico dos níveis de dependência espacial através de clusters e outliers. Essa 
análise foi importante para mensurar os níveis extremos de desigualdade populacional, de renda e de acesso aos serviços urbanos.

Essa pesquisa foi o resultado de esforços para colocar a análise sistêmica como uma categoria fundamental para a leitura e análise do espaço urbano. Ressalta-se que a análise espacial exploratória utilizada é somente uma ferramenta, dentre várias, para realizar diagnósticos urbanos e orientar políticas públicas.

Até o fim desse estudo, a estrutura da Região Metropolitana de Goiânia que havia sido alterada pela Lei Complementar $n^{\circ}$ 139/2018 - retirando o município de Inhumas e adicionando Santa Bárbara de Goiás - sofreu nova alteração em 2019, trazendo o município de Inhumas de volta para a RMG. Dessa forma, abre-se novas oportunidades de atualização deste estudo a partir da inserção desse município.

Essa pesquisa foi realizada com um enfoque mais global para o entendimento das relações entre a estrutura espacial e a mobilidade urbana, contudo, deixa-se ainda para pesquisas futuras uma abordagem mais abrangente de cada eixo a partir de outras variáveis e, ainda, o aprofundamento para o entendimento quantitativo dos níveis de interação entre esses sistemas.

\section{REFERÊNCIAS}

BRITO, L. C.; KNEIB, E. C. Impactos de áreas de expansão urbana na mobilidade e acessibilidade: a região sudoeste de Goiânia. In: KNEIB, E. C. (Org.). Projeto e cidade: mobilidade e acessibilidade em Goiânia. Goiânia: Editora UFG, 2016. p. 95-112.

CARDOSO, C. E. P. Dependência espacial. Setores censitários, Zonas OD, Distritos, Subprefeituras e etc. Setembro, 2007. Disponível em: http://www. sinaldetransito.com.br/artigos/espacial.pdf. Acesso em: 20 nov. 2018.

CASTRO, A. A. B. C.; MELO, R. A.; SILVEIRA, J. A. R.; SILVA, G. J. A.; LAPA, T. A. Interfaces rodoviário-urbanas no processo de produção das cidades: estudo de caso do contorno rodoviário de João Pessoa, PB, Brasil. Ambiente Construído, Porto Alegre, v.15, n. 3. p. 175-199, 2015.

CATALÃO, I. Brasília, metropolização e espaço vivido: práticas especiais e vida quotidiana na periferia goiana da metrópole. 1.ed. São Paulo: Cultura acadêmica, 2010. 156p.

CHAGAS, A. L. S. Econometria Espacial. Aula 3: A Análise Exploratória de Dados Espaciais. Universidade de São Paulo. São Paulo: março, 2016. Disponível em: https://edisciplinas.usp.br/pluginfile.php/990604/mod_resource/content/0/Aula\%203_2016.pdf. Acesso em: 25 nov. 2018.

DRUCK, S.; CARVAlHO, M. S.; CÂMARA, G.; MONTEIRO, A. V. M. Análise Espacial de Dados Geográficos. 1. ed. Brasília, EMBRAPA, 2004. 209p.

FERREIRA, F. Apresentação à edição brasileira. In: LYNCH, K. A imagem da cidade. São Paulo: Editora WMF Martins Fontes, 2011. 
GENTIL, C. D. A.; BEZERRA, M. C. L.; MEDEIROS, V. A. S. A forma urbana para a construção da mobilidade sustentável. Estudo de caso: Goiânia-GO. In: KNEIB, E. C. (Org.). Projeto e cidade: mobilidade e acessibilidade em Goiânia. Goiânia: Editora UFG, 2016. p. 47-71.

GONZAGA, A. S. S. Transporte público coletivo e acessibilidade na Região Metropolitana de Goiânia: um panorama da dinâmica metropolitana a partir de indicadores. 2017. 166 f. Dissertação (Mestrado em Projeto e Cidade) - Faculdade de Arquitetura e Urbanismo, Universidade Federal de Goiás, Goiânia, 2017.

HARRIS, Sabrina. Estrutura espacial urbana e mobilidade: o caso da Região Metropolitana de São Paulo. 2015. 118 f. Dissertação (Mestrado em Arquitetura) - Faculdade de Arquitetura e Urbanismo, Universidade de São Paulo, São Paulo, 2015.

INSTITUTO BRASILEIRO DE GEOGRAFIA E ESTATÍSTICA (IBGE). Estimativas da população residente no brasil e unidades da federação com data de referência em $1^{\circ}$ de julho de 2018. Agosto, 2018. Disponível em: $\mathrm{ftp}: / / \mathrm{ftp}$. ibge.gov.br/Estimativas_de_Populacao/Estimativas_2018/ estimativa_dou_2018.pdf $>$. Acesso em: 15 out. 2018.

INSTITUTO BRASILEIRO DE GEOGRAFIA E ESTATÍSTICA (IBGE). Sinopse do Censo Demográfico 2010. Rio de Janeiro: IBGE, 2011. 265p.

KASEMSOOK, A. Spatial and functional differentiation: A symbiotic and systematic relationship. In: INTERNATIONAL SPACE SYNTAX SYMPOSIUM, 4., 2003, London. Proceedings... London, 2003. p. 1-18.

KASPER, H. O processo de pensamento sistêmico: um estudo das principais abordagens a partir de um quadro de referência proposto. 2000. 291 f. Dissertação (Mestrado em Engenharia de Produção) - Faculdade de Engenharia, Universidade Federal do Rio Grande do Sul, Porto Alegre, 2000.

KNEIB, E. C. Apresentação. In: KNEIB, E. C. (Org.). Projeto e cidade: centralidades e mobilidade urbana. Goiânia: Gráfica UFG, 2014. p. 7-10.

MACEDO, M. H.; SILVA, A. N. R.; COSTA, M. S. Abordagem sistêmica da mobilidade urbana: reflexões sobre o conceito e suas implicações. 1. ed. São Carlos: STT/CETEPE/EESC/USP, 2008. $13 \mathrm{p}$.

MEDEIROS, A. Autocorrelação Espacial: Mapas de Cluster no ArcGIS. 2018. Disponível em: http://www.andersonmedeiros.com/como-fazer-mapas-de-cluster-no-arcgis/. Acesso em: 15 nov. 2018.

NETO, W. L; KNEIB, E. C. Centralidades e acessibilidade por transporte coletivo em Goiânia: análise exploratória de variáveis espaciais. In: KNEIB, E. C. (Org.). Projeto e cidade: mobilidade e acessibilidade em Goiânia. Goiânia: Editora UFG, 2016. p. 31-46.

OJIMA, R. Dimensões da urbanização dispersa e proposta metodológica para estudos comparativos: uma abordagem socioespacial em aglomerações urbanas brasileiras. Revista Brasileira de Estudos de População, São Paulo, v. 24, n. 2. p. 277-300, 2007. 
OLIVEIRA, J. P.; PORTELA, L. O. V. A cidade como um sistema: reflexões sobre a teoria geral de sistemas aplicada à análise urbana. Perspectivas Contemporâneas, Campo Mourão, v. 1, n. 2, p. 164-182, 2006.

PEDRO, L. M.; SILVA, M. A. V.; PORTUGAL, L. S. Desenvolvimento e mobilidade sustentáveis. In: PORTUGAL, L. S. (Org.). Transporte, mobilidade e desenvolvimento urbano. 1 ed. Rio de Janeiro: Elsevier, 2017. p. 19-37.

PIRES, A. C. F. Impactos do espraiamento urbano e relações metropolitanas no sistema de transporte coletivo: estudo de caso na Região Metropolitana de Goiânia. 2018. 220 f. Dissertação (Mestrado em Projeto e Cidade) - Faculdade de Arquitetura e Urbanismo, Universidade Federal de Goiás, Goiânia, 2018.

PORTUGAL, L. S.; MELLO, A. J. R. Um panorama inicial sobre transporte, mobilidade, acessibilidade e desenvolvimento urbano. In: PORTUGAL, L. S. (Org.). Transporte, mobilidade e desenvolvimento urbano. Rio de Janeiro: Elsevier, 2017. p. 1-17.

RIGOTTI, J. I. R. A análise exploratória de dados espaciais: breve introdução. Observatório das Metrópoles. Universidade Federal do Rio de Janeiro (UFRJ). Rio de Janeiro, 2005. Disponível em: http://www.observatoriodasmetropoles.ufrj.br/apresentacoes/6_ analise_exploratoria.pdf. (2005) Acesso em: 18 nov. 2018.

ZECHLINSKI, A. P. P. Configuração e práticas no espaço urbano: uma análise da estrutura espacial urbana. 2013. 136 f. Tese (Doutorado em Planejamento Urbano e Regional) - Faculdade de Arquitetura, Universidade Federal do Rio Grande do Sul, Porto Alegre, 2013.

Trabalho enviado em 13/09/2019

Trabalho aceito em 24/01/20 